\title{
The Toll of Natural Disasters on Education in Micronesia and the Needs of Education During Recovery
}

\author{
Michelle LaBrunda ${ }^{1}$, Mary Jane Miller ${ }^{2}$, Naushad Amin ${ }^{3}$ \\ University of South Florida ${ }^{1}$ \\ University of Guam ${ }^{2}$ \\ GloMed LLC ${ }^{3}$
}

\begin{abstract}
Micronesia is a large subregion of Oceana located north of the equator in the Pacific Ocean. It spans over 290,000 square miles and includes some 2500 islands, of which approximately 120 are populated. While cultural trends exist, the region is extremely diverse in its language and culture. Micronesia is located on the Ring-of-Fire and can be subject to a multitude of natural disasters including typhoons, earthquakes, floods, volcanic eruptions, tsunamis, and flooding due to climate change. Of these, typhoons, earthquakes, draughts, and flooding are most notable. Because the islands are remote, support small populations, and have frequent disasters, humanitarian aid efforts in the region require a unique approach. Worldwide, there is growing evidence that education during times of disaster is important for the health of the community, however, this aspect of recovery is often neglected. The available data for normal educational programs in Micronesia is limited and information regarding condition of education during times of recovery from natural disasters is even more incomplete.
\end{abstract}

\section{Introduction}

Humanitarian crisis can occur in any population from the smallest village to the largest city. Basic human needs vary little regardless of location; it is important, however, to understand that the response to every crisis cannot be undertaken in the same way. Certainly, every population needs water, food, shelter, medical care, and education, but humanitarian aid following natural disasters must be offered within the framework of the location, population and cultural traditions that exist. Population size, culture, geography, and weather all impact humanitarian efforts and the needs of children's education are often further down the list of restoration projects than they should be.

\section{Micronesia: Physical Aspects}

Micronesia is comprised of a culturally and linguistically diverse group of island nations. It is a subregion of Oceana located in the Pacific Ocean and comprised of approximately 2500 islands. The area is roughly divided into four main archipelagos each with numerous islands. The population is around 600,000 [1]. The region is prone to numerous types of natural disasters due to its unique geography and geology. Despite being one of the most disaster-prone areas in the world, the area is almost non-existent if one were to judge based on world media coverage.

Politically, Micronesia is divided into five countries and three US territories. The countries are the Federated States of Micronesia, Palau, Kiribati, Marshall Islands and Nauru. The US territories are Guam, US Minor Outlying Islands, and the Northern Mariana Islands. The Federated States of Micronesia has four large states, Yap, Chuuk, Pohnpei, and Kosrae, each with its own laws, culture, language group, and departments of education [2].

Micronesia lies along the "Ring of Fire". This is a zone of significant seismic and volcanic activity due to the convergence of the Pacific and Philippine tectonic plates resulting in the Pacific Plate being pushed under the Philippine plate [3]. Each Island is unique, but some generalities can be made. There are two types of islands, the more common volcanic and the less common atoll. Volcanic islands tend to have jagged hills, while the atoll islands are coral based and almost at sea level. Atolls are found all across the Micronesian region but the ones in the Marshall Islands and Kiribati are particularly troubled by rising sea levels [4]. These low-lying atolls are very susceptible to the effects of storms, tsunamis, and climate change. Micronesia has some of the most picturesque landscapes in the world. The cost of these beautiful island landscapes is the potential for damage from earthquakes, typhoons, tsunamis, and drought.

\section{Micronesia: Cultural Aspects}

Understanding of basic cultural norms is important in serving the needs of people in the wake of a natural disaster. In Micronesia there is not a single culture, rather there are many distinct cultures. Even within an island nation, language and cultural norms often differ from island to island. The islands are remote, and facilities vary greatly. Some are without running water or electricity, yet others are 
well developed with international phone systems and high-speed internet.

Family is of primary importance in all Micronesian societies. Family generally consists of more than just the basic nuclear family and includes a number of extended family members, and in some cases close friends. It is common for people from traditional Micronesian cultures to miss school, work, or other responsibilities due to family obligations [1].

There is rich linguistic diversity in Micronesia. Many of the languages only have a few thousand speakers or less and are considered endangered languages [5]. The major languages of the area, other than English, are Palauan, Yapese, Ulithian, Woleaian, Chuukese, Pohnpeian, Kosraean, Nukuoro, Kapingamarangi, Marshallese, Chamorro, Carolinian, and Kiribati (also called Gilbertese). Even if islands are geographically in close proximity, they may have completely unrelated native languages. English is the official language, or one of the official languages, on most of the islands, but not everyone speaks English. English is generally stated as the language of instruction in school, but daily lessons are often more in the local language than in English [6]. There can be differences in language even within the same tribal region based on gender and social status [7]. Following a natural disaster, if families from more than one island are evacuated to a common area it is important to keep in mind that they are unlikely to have identical language backgrounds.

Each Micronesian culture is comprised of a unique combination of social, cultural, and linguistic features that directly impact the people, the education system and how these societies will respond to disasters and disaster recover.

\section{Education System in Micronesia}

Before discussing education in the context of humanitarian disasters there must be a basic understanding of the educational systems in Micronesia. As with so many aspects of Micronesian culture, there is a great deal of diversity in education systems.

Education is important in the Micronesian islands, but sometimes in a different way than in Western countries. Traditional education systems involved parents and elders informally instructing the younger generation. In some island cultures children are discouraged from asking questions or making eye contact with the teacher or other adult. They may seldom be allowed to speak to elders since this could be considered rude. Individualism and competition in the educational environment were discouraged. In some areas, aspects of these traditional educational practices still linger in the education system. Micronesian students typically work well in groups but may have difficulty with direct discussions [2]. This general tendency may extend into adult society when working with humanitarian aid groups. Westerners may find less apparent responsiveness to an "authority figure" than they expect, but as a cultural norm, perhaps it should be anticipated.

\section{Types of Natural Disaster}

The majority of the Micronesian islands are north of the equator and classified as tropical. The seasons consist of the rainy season from July to October and the dry season from November to June. In addition to finding itself on the Ring-of-Fire, Micronesia is also in a region called "Typhoon Alley". Typhoon Alley is the most active region in the world for tropical storms. Typhoon is the Pacific regional name for tropical storms of hurricane strength, but typhoons are often more powerful than their counterparts in the Atlantic. Since the year 2000 , the area has been ravaged by over 40 supertyphoons. This is almost four times the number of hurricanes seen in the Atlantic. This occurs because the Pacific Ocean is larger so after a storm forms there is a larger amount of surrounding warm water in which it can gain strength without colliding with a land mass. Some houses and buildings on the islands are built to withstand severe storms, but many more are damaged or destroyed during severe weather events.

Micronesia is a seismically active region due to the movement of tectonic plates. Challenger Deep in the Marianas trench is the deepest known point on the planet at 10,916 meters deep. To put this in perspective, if Mount Everest were placed on the bottom of the trench it would be covered by a mile of water. As the Pacific and Philippine plates collide, they not only produce volcanoes and deep trenches, but also earthquakes. While active volcanoes do exist in the region, they are generally not a source of serious natural disasters. However, Micronesia is an extremely seismically active area. In a typical 30day period in 2018, there were over 120 earthquakes greater than or equal 2.5 on the Richter scale, and in the last 40 years there have been at least 4 earthquakes in the region that rated 7.0 or higher on the Richter scale [8].

In coastal regions, earthquakes have serious consequences in the form a tsunamis, although not all earthquakes produce tsunamis. Earthquakes rated 6.5 or higher are more likely to cause tsunamis and earthquakes in locations outside of Micronesia can send tsunamis to the islands. Low amplitude, shallow earthquakes are the most likely to cause tsunamis because they are most likely to move the seafloor and displace large quantities of water. The impact of tsunamis on the Micronesian islands varies 
depending on the structure of the island, direction and size of the wave, and location of the population [9]. Atoll islands tend to have a low elevation and tsunamis in these locations can be severe [10].

Disruptions in rainfall patterns can also lead to natural disaster in the form of draught. While there are 2500 islands in Micronesia, just over 120 of them are inhabited. One of the required features for an island to be inhabited is that it must have a consistent supply of fresh drinking water. The source of the water varies from island to island. On Guam, freshwater is obtained from aquafers that run below the island [11]. Here, as in most islands, rainwater is the source of the aquafers, streams, and groundwater. Kosrae, however, has a plentiful supply of surface water due to the high rainfall, but very little groundwater. Rural residents depend entirely on rainwater catchment systems [12]. In Yap, most people use stream water for drinking although it is filtered and distributed through a local utility. Groundwater is also available for occasions when the streams become dry.

\section{Disasters in Micronesia and Education Impact}

Micronesian cultures are resilient, but they exist in an area prone to disasters. Typhoons are a yearly occurrence in the region and generally are the source of greatest destruction. Depending on the year, many of the Micronesian islands experience typhoon damage to one degree or another. During typhoon threats, evacuation options are very limited. There are few flights from these islands and many islands have no airport or landing facilities at all. In addition, the flights that do exist are expensive and may be suspended days before the typhoon occurrence. It is unlikely one can simply drive to a safe location, and boats are not safe on storm-tossed waters (Haretaligiye, 2018).

An example of the difficulties imposed on education following a natural disaster is in the aftermath of Typhoon Yutu. On October 25, 2018 Super-typhoon Yutu hit Saipan, Tinian, and Rota in Micronesia. Despite sustained wind speeds of 180 mph and widespread destruction in American territory, the media barely took notice. Only two died, but thousands were left homeless and power was out in some areas for several months on Tinian and Saipan [13]. The local economy is dependent on tourism, but for months the islands were not in a condition to receive tourists. The airports were heavily damaged and commercial flights were suspended for several weeks. If the typhoon were not enough, in the aftermath of the storm a fire broke out on Saipan further damaging buildings and infrastructure. Without electric power there was no way to pump water for extinguishing the fire, so it burned uncontrolled for hours [13].

Education in Saipan and Tinian came to a virtual halt for several weeks but was gradually resumed. Schools needed a great deal of repair work and three weeks after the event, the US government provided one-million dollars to build temporary education centers. However, the reality is that these islands are remote, and it takes time for supplies to arrive after they have been purchased [14]. Even as the rubble was cleared and repairable structures were reconstructed, school could not resume until water and electricity were available. But even then, culturally, the children were not expected to attend school until the work was finished at home. Children are part of the family and family takes precedence over any other activity. Some families considered home to include more than just making the house clean, safe and dry; it included yard clean up, street clearing, and even helping neighbors to rebuild. Many children lost a significant number of instructional days in the wake of Typhoon Yutu (Joshua, 2018).

As climate change continues to heat the planet, rising sea levels are increasingly a source of life disruption in Micronesia. A notable example is the "sinking" of Kiribati. Sea level rise is a slow insidious process that is expected to flood all of the nation's 33 islands. Numerous models have attempted to show the effect of climate change on sea levels and various estimates have emerged. The available data has been reviewed and the Intergovernmental Panel on Climate Change (IPCC) predicts the sea level rise to be between 0.40 and 0.63 meters by 2100 [15]. By the year 2100 it is expected that the ice sheets of Greenland and Antarctica will largely melt resulting in changes to at least $70 \%$ of coastal areas worldwide [15]. All continents will experience loss of coastal areas to some degree or another and Island nations are particularly at risk of damage from flooding due to global warming. Although not every flood in Kiribati is a result of sea level rise, the majority of inhabitants have already felt the impact of rising waters [4]. The government of Kiribati has purchased land in Fiji as a site of relocation for the time when Kiribati becomes unlivable and inhabitants can move to Fiji when they feel the time is right. There are no plans for forced relocation.

Kiribati is one of the world's poorest countries, but even with this status every student is educated on global warming. So far, schools themselves have been generally safe from flooding, but the communities where children live have been greatly impacted. When there are floods between students and their school, they are unlikely to go to school. This results in a number of instructional days missed. Flooding and flood damage can give rise to increased responsibilities for children at home. If there is 
damage to their homes, the tradition is to remain home to clean and rebuild rather than return to school. As sea water increasingly invades homes and businesses there is more than just the physical damage to property that is of concern. Anxiety resulting from uncertainty can have a strong effect on the emotional or psychological well-being of children. Preparing for a future in the face of such uncertainty makes the need for education even more critical while the disaster itself imperils the ability of residents to adequately provide it.

These are just two examples to illustrate the impact of disasters on education in Micronesia. What the rest of the world perceives as disaster is often just a part of the daily life in Micronesia. There are thousands of islands, most with few inhabitants, a unique language, and cultural traditions that may not value Western style education. In addition to typhoons and floods, the region is prone to earthquakes, tsunamis, and droughts. Despite the number of disasters affecting the area, the number of people impacted is small, so there is little worldwide attention, a paucity of research in the region, and incomplete humanitarian assistance programs that often lack a plan of action for education.

\section{Education and Disaster Response in Micronesia}

Humanitarian response planning and action should include education programs as an important part of the response. Continued education for children during emergencies is important for numerous reasons. Education allows children to be educated on the current state of the disaster, related safety issues, and taught how to respond to regionally specific emergencies. Continuing school also gives children a sense of normality and can help them cope with the stress of an emergency situation.

In addition, UNESCO lists nine specific impacts of education. These are 1) increased tolerance, 2) economic growth, 3) environmental awareness, 4) decreased teenage pregnancy rate, 5) improved child health, 6) improved maternal health, 7) better nutrition, 8) job creation, and 9) empowering women [16]. Long term disruption in education can negatively impact each of these areas. Unfortunately, despite evidence supporting the positive impact of prioritizing education during humanitarian assistance programs, only $2 \%$ of humanitarian aid is spent on education [17].

Much of the relief from disasters in Micronesia is done by FEMA. FEMA has extensively available public records. FEMA reports emphasize water, medical, and power related issues including restoring roads and supporting hospitals [18]. These are clearly important priorities, however, there is almost nothing published on education program impact and planning. Removal of debris blocking school structures is the only education related FEMA report from the region [19]. The Red Cross has also been involved in providing humanitarian aid in Micronesia, but again, there is no mention of resources being dedicated to educational efforts.

\section{Challenges}

There are numerous challenges facing those who attempt to provide education during humanitarian crises in Micronesia. The first of these is the diversity of underlying cultural values. In most Micronesian cultures there are those who value traditional lifestyles and shun foreign involvement. On the other extreme, there are those who long for the opportunities and wealth brought by quality education. It is difficult to implement an effective educational program during a disaster without a unified regional opinion.

Other challenges are logistical. Most islands are remote, not accessible by air travel, and subject to the whims of ocean currents and weather. It is expensive and time consuming to ship supplies, and the number of inhabitants on each island is small making aid efforts in the region less economical. Also, it may be difficult to include all populations. There are literally thousands of islands in Micronesia. While not all islands sustain populations, one typhoon can impact many that do. Logistically, the challenges in bringing humanitarian aid with a comprehensive education program to these regions are daunting.

Also, the basic education system is different from country to country within Micronesia. Guam and other US territories follow the US system and regulations, but others have developed their own educational program based on local needs. Many of the islands only require nine years of education and it is common for students to repeat years of education. What one would consider a fourth-grade level class may include teenagers and young adults depending on the location. With such a variety of educational structures it is challenging for humanitarian aid programs to address the needs of each individual school.

Accountability is inherent to the humanitarian aid process. Many traditional Micronesian social systems include a type of caste system with one's family and close friends at the center. It is common for wealth and ownership to be considered in terms of the larger group rather than the individual. Traditionally, these systems include showing preference to and doing favors for those in one's family, members of higher social standing or for an extended social group [20]. Humanitarian aid resources in these systems can be easily misdirected 
if not under close supervision. Supervision itself can be costly and can create conflict if it disrupts traditional practices.

\section{Conclusion}

A unique approach to education during humanitarian relief efforts is needed for the diverse islands scattered across Micronesia. It is important to involve those who know the diverse education systems, the culture, and local customs. Involving educators in disaster planning and mitigation efforts would be a cost-effective form of promoting continued education during disaster recovery.

Even during the worst disasters in Micronesia, few people are actually displaced. That means that the children as well as their teachers remain in the effected location. Infrastructure may have been destroyed including roads and school buildings, but most islands are not so large that traveling to a makeshift school is prohibitive. One of the barriers that does limit education is destruction of educational materials during disaster events.

Cost effective and appropriate humanitarian intervention should be directed at replacing basic teaching materials, providing temporary school structures, and having a preparedness plan. This plan should include step by step information for educators on how to respond in the post-disaster period. It should instruct educators to collect information and pass that information on to a central education department that can organize educational relief efforts. The educators should provide information including, what educational materials have been destroyed and need to rapidly be replaced, the status of the interior of the school room, and the impact of the disaster on the students.

It is also important that, even before the occurrence of any natural disaster, basic information is collected and stored in a safe location. This is a vital aspect of pre-disaster planning and the information should answer the following questions: How many schools are there? What is the basic education system? How many students are in each grade at each school? What is the status of each school building prior to the disaster? What supplies are present in the school prior to the disaster? If this information were to be collected in one central location, then as educators reported back to the central location with post-disaster information it would facilitate the process of resuscitating the education process and allow funds to be more rapidly secured.

The pre-disaster planning process should also focus on how to preserve educational materials. It is costly and time consuming to ship books, paper and other educational materials to Micronesia even under ideal conditions. During times of disaster it is even more difficult. Typhoons are one of the most common disaster events to impact Micronesia, and unlike earthquakes, typhoons are predicable at least a day or two in advance of the event. When typhoons are in route educators could have a standardized protocol in place to protect books and other essential educational materials. Dedicated low-profile waterproof boxes that can be securely tied down or safely stored during storms are economical and would help protect difficult to replace textbooks and materials from the storm.

There are no simple solutions to advancing education in times of humanitarian aid in Micronesia. The region is prone to disasters, is quite remote, and inhabited by culturally and linguistically diverse populations. Each community must decide on its priorities and develop an appropriate mitigation plan to minimize educational losses.

\section{References}

[1] 31st MEU's Typhoon Relief Mission in Saipan. (2015, August 21). Retrieved November 30, 2018, from FEMA: https://www.fema.gov/news-release/2015/08/21/31stmeus-typhoon-relief-mission-saipan

[2] Arui, R., Takahashi, T., Kodaira, S., Kaiho, Y., Nakanishi, A., Fujie, G., . . Kaneda, Y. (2016). Structure of the tsunamigenic plate boundary and low-frequency earthquakes in the southern Ryukyu Trench. Nature Communications, 12255. Retrieved from November 29, 2018 from, https://www.ncbi.nlm.nih.gov/pmc/articles/ PMC4961848/

[3] Church, J.A., P.U. Clark, A. Cazenave, J.M. Gregory, S. Jevrejeva, A. Levermann, M.A. Merrifield, G.A. Milne, R.S. Nerem, P.D. Nunn, A.J. Payne, W.T. Pfeffer, D. Stammer and A.S. Unnikrishnan, 2013: Sea Level Change. In: Climate Change 2013: The Physical Science Basis. Contribution of Working Group I to the Fifth Assessment Report of the Intergovernmental Panel on Climate Change [Stocker, T.F., D. Qin, G.-K. Plattner, M. Tignor, S.K. Allen, J. Boschung, A. Nauels, Y. Xia, V. Bex and P.M. Midgley (eds.)]. Cambridge University Press, Cambridge, United Kingdom and New York, NY, USA.

[4] Endangered Languages project. (nd). (Allegiance for Linguistic Diversity) Retrieved November 30, 2018 from Pacific Region: http://www.endangeredlanguages.com/ lang/region/Pacific.

[5] FEMA. (2015, August 21). Concrete Utility Poles Installed in Saipan. Retrieved December 2, 2018, from FEMA: https://www.fema.gov/news-release/2015/08/25/ concrete-utility-poles-installed-saipan.

[6] Fresh Water in Micronesia. (2015). Retrieved November 28, 2018, from PREL: http://w4l.prel.org/wpcontent/uploads/2015/01/wfl-island-overview-guide.pdf

[7] Gingerich, S. (2003). Water-Resources Investigation Report 03-412. U.S. GEOLOGICAL SURVEY. Retrieved December 5, 2018, from https://pubs.usgs.gov/wri/ wri034126/htdocs/wrir03-4126.html 
[8] Haretaligive, M. (2018, July). (M. J. Miller, Interviewer) Yap, Micronesia.

[9] Joshua, T. (2018, November 14). nterior Provides More Than \$1.6 Million to Help Northern Mariana Islands with Recovery from Super Typhoon Yutu. Office of Insular Affairs. Retrieved November 30, 2018, from https://www.doi.gov/oia/interior-provides-more-16-million -help-northern-mariana-islands-recovery-super-typhoonyutu.

[10] Keating, E. (1997). Honorific possession: Power and language in Pohnpei, Micronesia. Language in Society, 26(2), 247-268.

[11] Oakes, R., Andrea, M., \& Campbell, J. (2016). Kiribati: Climate change and migration- Relationships between household vulnerability, human mobility and climate change. (Vol. report 20). Bonn: United Nations University Institute for Environment and Human Security (UNU-EHS).

[12] Owuor Otieno, M. (2017, September 25). What Languages Are Spoken In The Federated States Of Micronesia? Retrieved November 15, 2018, from World Atlas: https://www.worldatlas.com/articles/what-languages-are-spoken-in-the-federated-states-of-micronesia.html.

[13] People of Micronesia. (2017, January 17). Retrieved November 11, 2018, from Guampedia: https://www.guampedia.com/people-of-micronesia/.

[14] Policy Paper 21. (2015). Humanitarian Aid for Education: Why It Matters and Why More is Needed. Education for All Global Monitoring Report. Retrieved November 30, 2018, from http://s3.amazonaws.com/ineeassets/resources/EFA_GMR_-_Humanitarian_Aid_for_ Education_Policy_Paper_June_2015.pdf.

[15] Rehman, H., Nakaya, H., \& Kawai, K. (2013). Geological Origin of the Volcanic Islands of the Caroline. South Pacific Studeies, 101-118. Retrieved December 3, 2018 from http://cpi.kagoshima-u.ac.jp/publications/ southpacificstudies/sps/sps33-2/South\%20Pacific\%20 Studies\%2033(2)\%20pp101-118.pdf.

[16] UNESCO. (2017). Education Transforms Lives. France: United Nations Educational, and Cultural Publissher. Retrieved November 29, 2018, from http://unesdoc.unesco.org/images/0022/002231/223115E.p df.

[17] USGS. (2018). US Geological Service. Retrieved from National Earthquake Hazards Reduction Program. Retrieved November 30, 2018 from, https://earthquake.usgs.gov/earthquakes/map/\#\%7B\%22fe ed $\% 22 \% 3 \mathrm{~A} \% 221541948040232 \% 22 \% 2 \mathrm{C} \% 22$ sort $\% 22 \% 3$ A $\% 22$ newest $\% 22 \% 2 \mathrm{C} \% 22$ mapposition $\% 22 \% 3 \mathrm{~A} \% 5 \mathrm{~B} \% 5$ B-19.36\%2C-216.563\%5D\%2C\%5B27.013\%2C$156.094 \% 5 \mathrm{D} \% 5 \mathrm{D} \% 2 \mathrm{C} \% 22$ viewModes $\% 22 \% 3 \mathrm{~A} \% 5 \mathrm{~B} \% 22$ list $\% 22 \% 2 \mathrm{C} \% 22 \mathrm{map} \% 22 \% 5 \mathrm{D} \% 2 \mathrm{C} \% 22$ autoUpdate $\% 22 \%$ [18] USGS. (2018b). Retrieved November 23, 2018, from What is it about an earthquake that causes a tsunami?: https://www.usgs.gov/faqs/what-it-about-earthquakecauses-a-tsunami.
[19] Wahilani, K. (2011). Education and the Micronesian Culture. Retrieved November 29, 2018, from https://laulima.hawaii.edu/access/content/user/jaydene/ED 294/ED294.Diversity.gp.sample2.pdf

[20] Wong, A., \& Cruz, L. (2018, November 14). The Media Barely Covered One of the Worst Storms to Hit U.S. Soil. The Atlantic. Retrieved November 28, 2018, from https://www.theatlantic.com/science/archive/2018/11 /super-typhoon-yutu-mainstream-media-missed-northernmariana-islands/575692/. 